\title{
Catalytic asymmetric oxo-Diels-Alder reactions with chiral atropisomeric biphenyl diols
}

\author{
Chi-Tung Yeung ${ }^{1,2}$, Wesley Ting Kwok Chan ${ }^{2}$, Wai-Sum Lo ${ }^{1,2}$, Ga-Lai Law ${ }^{1,2}$ \\ and Wing-Tak Wong ${ }^{* 1,2}$
}

\author{
Full Research Paper \\ Address: \\ ${ }^{1}$ The Hong Kong Polytechnic University Shenzhen Research Institute, \\ Shenzhen, PR China and ${ }^{2}$ State Key Laboratory of Chemical Biology \\ and Drug Discovery, Department of Applied Biology and Chemical \\ Technology, The Hong Kong Polytechnic University, Hung Hom, \\ Kowloon, Hong Kong \\ Email: \\ Wing-Tak Wong* - w.t.wong@polyu.edu.hk \\ * Corresponding author \\ Keywords: \\ asymmetric organocatalysis; axial chirality; biaryls; hydrogen bond; \\ oxo-Diels-Alder reaction
}

Beilstein J. Org. Chem. 2019, 15, 955-962. doi:10.3762/bjoc. 15.92

Received: 11 December 2018

Accepted: 30 March 2019

Published: 18 April 2019

Associate Editor: M. Rueping

(C) 2019 Yeung et al.; licensee Beilstein-Institut. License and terms: see end of document.

\begin{abstract}
New chiral atropisomeric biphenyl diols 3, 4 and $\mathbf{6}$ containing additional peripheral chiral centers with different steric bulkiness and/or electronic properties were synthesized. The X-ray crystal structure of $\mathbf{3}$ shows the formation of a supramolecular structure whereas that of $\mathbf{6}$, containing additional $\mathrm{CF}_{3}$ substituents, shows the formation of a monomeric structure. Diols $\mathbf{1}-\mathbf{6}$ were found to be active organocatalysts in oxo-Diels-Alder reactions in which 2 recorded a $72 \%$ ee with trimethylacetaldehyde as a substrate.
\end{abstract}

\section{Introduction}

The Diels-Alder (DA) reaction is a useful and easy-to-perform method for the synthesis of six-membered rings through the direct formation of $\mathrm{C}-\mathrm{C}$ bonds between a diene and a dienophile (a substituted alkene); it is called a hetero-Diels-Alder (HDA) reaction when one or more heteroatoms (most often oxygen or nitrogen) are present among the reactants, such as the use of carbonyl compounds or imines as dienophiles [1-5]. An asymmetric HDA reaction is capable of introducing up to four stereogenic centers in a one-step [4+2] cycloaddition or cyclization reaction [6-8] and it has become hugely popular in preparing vital intermediates for the syntheses of key structural subunits of natural products with biological activities (e.g., carbohydrates, antibiotics, toxins etc.) $[9,10]$. Alternate synthetic pathways include ring formations of open-chained precursors $[11,12]$, reactions of dicarbonyl compounds with ketene diethylacetal followed by hydrolysis [13] or total syntheses [14]; however, none of these alternatives could rival the combination of ease and cost-effectiveness of HDA reactions.

Oxo-Diels-Alder (oxo-DA) reactions between electron-poor aldehydes and electron-rich dienes such as Danishefsky's dienes or Brassard's dienes are efficient ways to construct 
oxygen-containing six-membered heterocycles via [4 + 2] cyclizations, and have been dominated by metal-based chiral Lewis acid catalysts for over three decades [15-26]. Comparatively, interest in the utilization of metal-free organocatalytic oxo-DA reactions began to grow only after Rawal's group reported a ground-breaking contribution in using a diol molecule, TADDOL, as a hydrogen bonding organocatalyst for the reaction between 1-dimethylamino-3-tert-butyldimethylsilyloxy1,3-butadiene (Rawal's diene) and aldehydes with excellent enantioselectivities (aromatic aldehyde: up to 86-98\% ee) in 2003 [27]. Activation via a single-point hydrogen bond between one of the hydroxy groups of the TADDOL and the carbonyl oxygen of the aldehyde was proposed to be a crucial factor for the success of this organocatalyst in the reaction. Two years later, they reported another efficient diol-based hydrogen bonding organocatalyst, BAMOL, for catalyzing the same oxo-DA reactions with a library of aldehydes (aromatic: $97-99 \%$ ee; aliphatic: $84-98 \%$ ee) [28]. Thereafter, many different kinds of hydrogen bonding-based organocatalysts have been developed for oxo-DA reactions [29-35]. One kind of organocatalyst in particular, which is based on an oxazoline template with hydroxy and $\mathrm{NH}$ units for hydrogen bonding activation, $\%$ ee and yields in oxo-DA reactions were found to be enhanced with increasing $\mathrm{NH}$ acidity, leading to stronger hydrogen bonds [32]. So, there is much room for further investigation and improvement with other hydrogen bonding organocatalysts.

An earlier work by Goldfuss and his co-worker on an atropisomeric biphenyl compound showed that atropisomerism can be induced and stabilized with hydrogen bonding from fenchyl alcoholic units [36]. Regarding to atropisomeric properties of biphenyl compounds, our group have previously reported the formation of supramolecular helices or dimers through intermo- lecular hydrogen bonding of two axially chiral biphenyl hybrid diols (1 and $\mathbf{2}$ in Scheme 1) which contain point chirality at the side arms and axial chirality at the biphenyl backbone [37]. We envisage the structural similarity and the ability of our scaffold to form strong hydrogen bonds could perform the same catalytic role in oxo-DA reactions as reported in the literature. Inspired by Rawal's work on TADDOL and BAMOL organocatalysts, we, in this work, have adopted a similar reaction of Rawal's diene with benzaldehyde as a starting point of our study and other biphenyl hybrid diols with different steric bulky substituents were incorporated (3 and 4). Since it is known that the catalyst acidity has significant influence on hydrogen-bond-catalyzed reactions [32], we also incorporated a $\mathrm{CF}_{3}$ group in our molecular scaffold to investigate how it would affect the reactivity and selectivity (5 and 6). Recently, we found that compound $\mathbf{5}$, which can form a pair of atropisomer $(P)-(R, R)-\mathbf{5}$ and $(M)-(R, R)-\mathbf{5}$, gave different results in $N$-nitroso aldol reactions compared to $\mathbf{1}$ [38].

\section{Results and Discussion Synthetic procedures}

Synthetic steps of catalyst $\mathbf{3}$ were similar to that for $\mathbf{1}$ and $\mathbf{2}$ [37]. Asymmetric reduction of the carbonyl group of 2'-bromobenzophenone (a) with borane dimethyl sulfide in the presence of $(S)$-(-)-2-methyl-CBS-oxazaborolidine catalyst gave $(S)$-(2-bromophenyl)(phenyl)methanol $(S)$-b in $93 \%$ yield and $94 \%$ ee (Scheme 2 and Figure S1 in Supporting Information File 1). Homo-coupling of $(S)$-b with $\mathrm{Ni}(\mathrm{COD})_{2}$ was achieved with very high diastereoselectivity and only a single atropisomer was formed. The X-ray crystal structure showed that it is $(M)-(S, S)-3$ (Figure 1$)$. This high atropstereoselectivity is believed to be due to the energetically unfavorable formation of the other atropisomer $(P)-(S, S)-\mathbf{3}$ as a higher steric repulsion<smiles>CC(O)c1ccccc1-c1ccccc1C(C)O</smiles>

1<smiles>Cc1cc(C)c([C@H](O)c2ccccc2-c2ccccc2[C@@H](O)c2c(C)cc(C)cc2C)c(C)c1</smiles>

4<smiles>CC(C)(C)[C@H](O)c1ccccc1-c1ccccc1[C@@H](O)C(C)(C)C</smiles>

2<smiles>CC(O)(c1ccccc1-c1ccccc1C(C)(O)C(F)(F)F)C(F)(F)F</smiles>

5<smiles>OC(c1ccccc1)c1ccccc1-c1ccccc1[C@H](O)c1ccccc1</smiles>

3<smiles>C[C@](O)(c1ccccc1)c1ccccc1-c1ccccc1C(O)(c1ccccc1)c1ccccc1</smiles>

6 


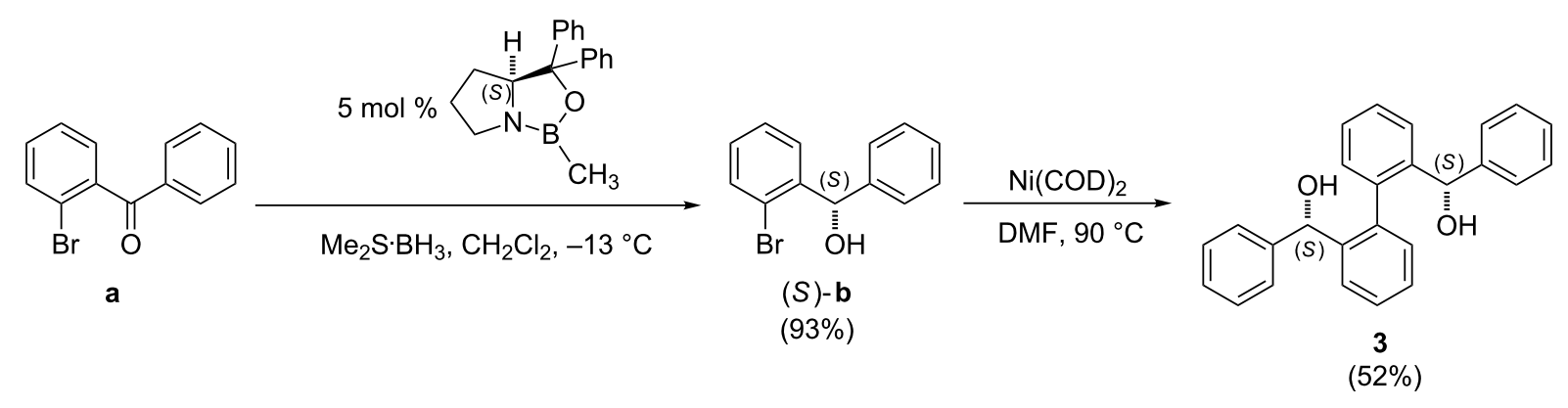

Scheme 2: Synthesis of 3.

(a)

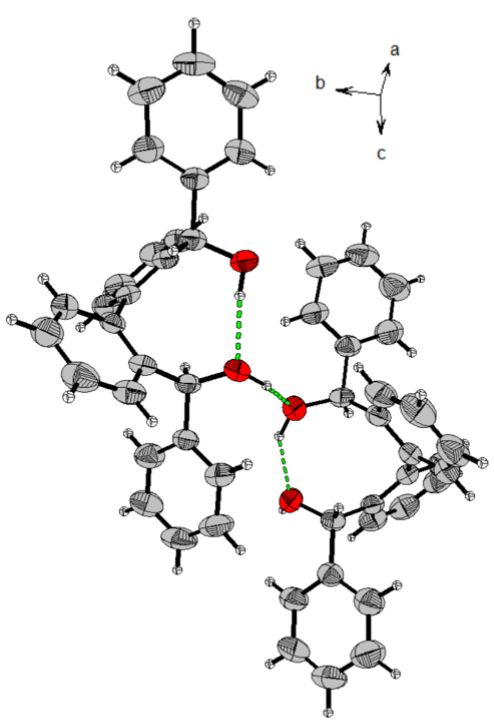

(b)

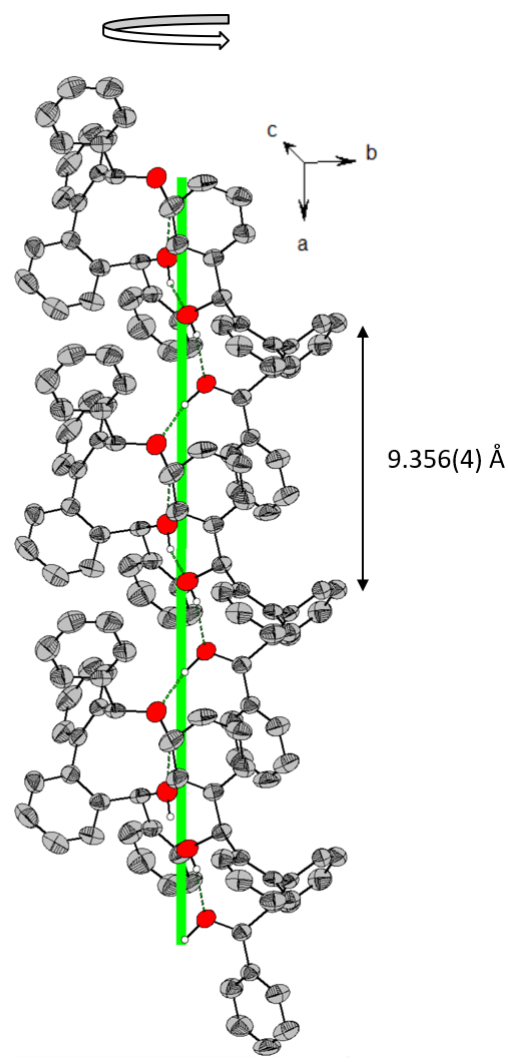

Figure 1: (a) Single crystal X-ray structure of 3: showing intra- and intermolecular hydrogen bonds (green dashed line). Torsion angles of biphenyl rings is $76.25(35)-78.27(35)^{\circ}$; axial configuration is $M$. (b) Crystal packing of $\mathbf{3}$ shows one strand of supramolecular left-handed helixes (hydrogens that are not involved in interactions are omitted for clarity).

is generated during the close approach of two bulky phenyl peripheral substituents. The X-ray crystal structure also reveals that an alternative formation of intra- and intermolecular hydrogen bonds [intra- $\mathrm{D}(\mathrm{OH} \cdots \mathrm{O}): 1.951(3) \AA$; inter- $\mathrm{D}(\mathrm{OH} \cdots \mathrm{O})$ : $1.822(3) \AA]$ led to an enantiomerically pure infinite helical supramolecular structure. In contrast, only a dimeric structure was observed for the corresponding racemic mixture [39]. In our case, atropisomerization from $(M)-(S, S)$ to $(P)-(S, S)$ was not observed in solution.
For catalyst 4, different from the synthesis of catalyst $\mathbf{3}$, asymmetric reduction of the corresponding ketone, (2-bromophenyl)(mesityl)methanone c, using (S)-(-)-2-methyl-CBSoxazaborolidine as the catalyst resulted in a very low enantioselectivity ( $<15 \%$ ee) of the product, (2-bromophenyl)(mesityl)methanol (d, Scheme 3). For this reason, another strategy of obtaining high \% ee of $\mathbf{d}$ was employed. Chiral resolution of racemic-d with $(R)$-menthyl chloroformate gave a high \% ee of this key intermediate d. After column chromatographic purifica- 


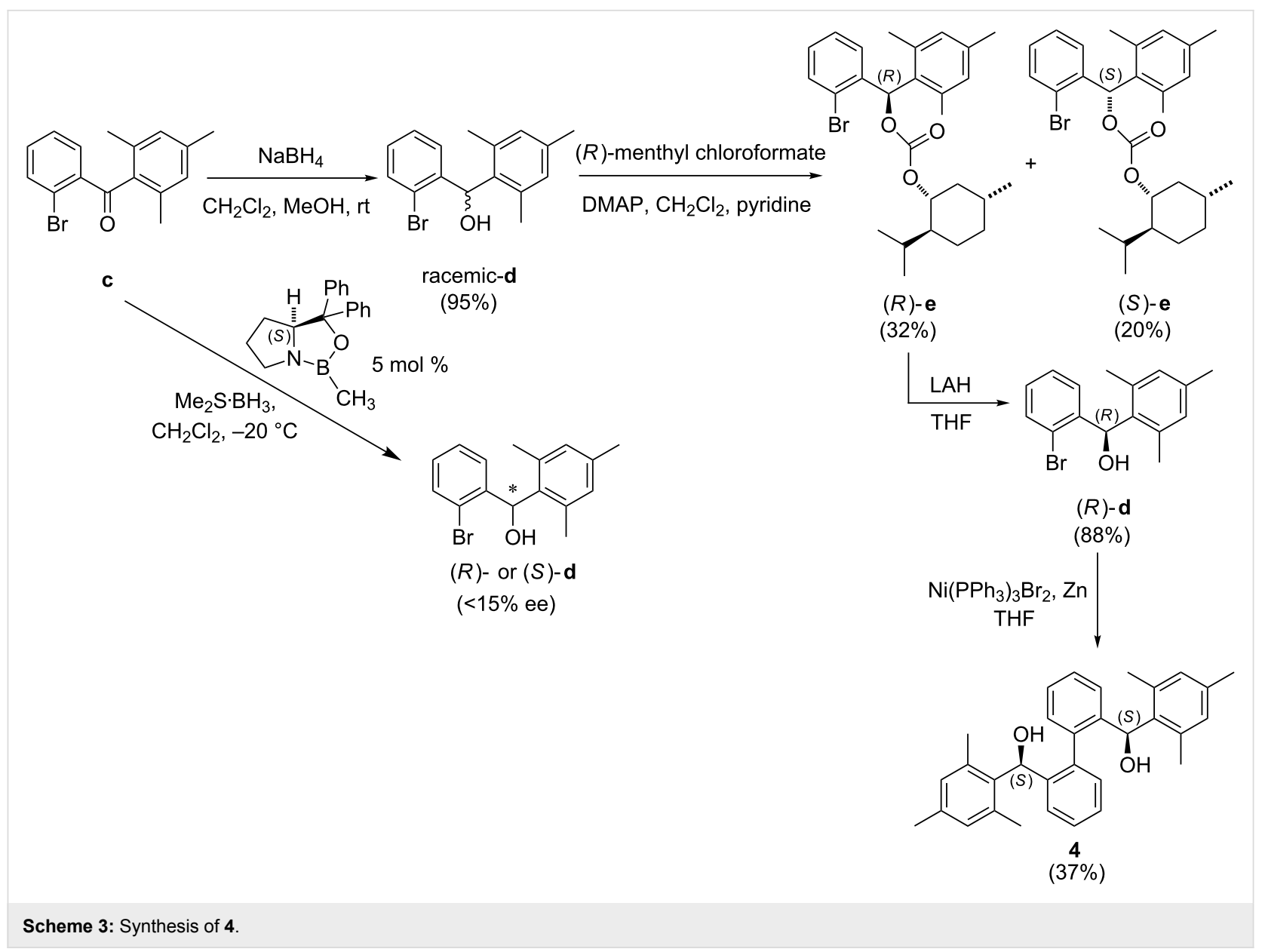

tion of the crude reaction mixture, the corresponding diastereomers $(R)$-e or $(S)$-e can be partly separated. Their diastereoselectivities can be further enhanced by slow evaporation of the corresponding diastereomers from acetonitrile and the absolute configuration of one diastereomer was confirmed with X-ray crystal structure (Supporting Information File 1, Figure S2). After removing the chiral-resolving menthyl substituent with lithium aluminium hydride (LAH), the enantioselectivity of (R)-d was higher than $99 \%$ ee when checked with HPLC (Supporting Information File 1, Figure S3). Catalyst 4 was then obtained by homo-coupling of $(R)$-d with $\mathrm{Ni}\left(\mathrm{PPh}_{3}\right)_{3} \mathrm{Br}_{2} / \mathrm{Zn}$ with $37 \%$ yield. The low yield of catalyst 4 may be due to steric bulkiness of the mesityl group that hampers close approach of $\mathbf{d}$ during coupling.

For the synthesis of catalyst $\mathbf{6}$, the $\mathrm{CF}_{3}$ substituent was introduced to $\mathbf{f}$ by trifluoromethylation (Scheme 4). A racemic mixture of $\mathbf{g}$ was obtained after the TMS group was removed with TBAF. This racemate then underwent chiral resolution by reacting with $(1 S)-(-)$-camphanic chloride to give a diastereomeric mixture of $(R)$-h or $(S)$-h. After separating these diastereomers by column chromatography, the absolute configura- tion of $(S)$-h was checked with its X-ray crystal structure (Supporting Information File 1, Figure S4). The optically pure (S)-g was then obtained by removing the chiral camphanic substituent (Supporting Information File 1, Figure S5) and (S)-g was then utilized for homo-coupling with $\mathrm{Ni}(\mathrm{COD})_{2}$ to give catalyst 6. X-ray crystal structure of 6 showed that it is an $(P)-(S, S)$ atropisomer (Figure 2). From the structure, no extensive intermolecular $\mathrm{OH} \cdots \mathrm{O}$ hydrogen bonds can be found for the formation of the supramolecular structure. Instead, intramolecular hydrogen

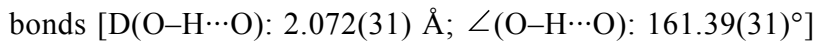
were found to keep the conformation of the biphenyl ring intact. Relative spatial arrangement of the larger phenyl substituent is located at the side where it is relatively far away from the intramolecular hydrogen bond unit.

\section{Catalytic studies}

With the organocatalyst $\mathbf{1}$ in hand, we firstly examined the oxoDA reaction of benzaldehyde and Rawal's diene in standard conditions. The reaction was found to be very sluggish when performed at $-40{ }^{\circ} \mathrm{C}$. However, at $-20^{\circ} \mathrm{C}$, better yields were obtained. The reactions with organocatalysts 1-4 showed moderate yields (41-64\%) of the catalytic product (2,3-dihydro-2- 
<smiles>O=C(c1ccccc1)c1ccccc1Br</smiles>
1) $\mathrm{TMSCF}_{3}, \mathrm{CsF}$, neat 2) TBAF, THF, rt<smiles>OC(Cl)(Cl)C(Cl)(Cl)c1ccccc1</smiles>

$(78 \%)$

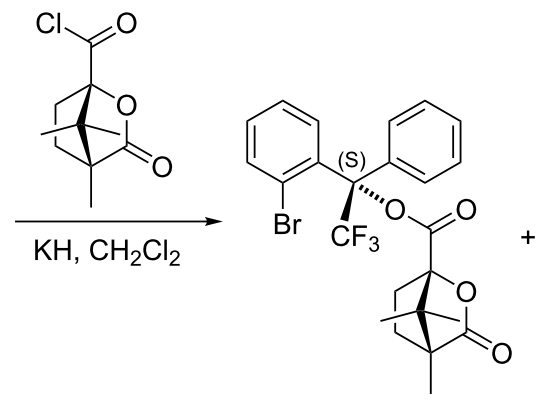

(S)-h

(33\%)<smiles>O=[N+]([O-])O</smiles>

(S)-g

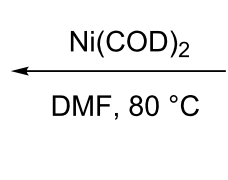<smiles>CC(OC(=O)C12CCC(C)(C(=O)O1)C2(C)C)(c1ccccc1)c1ccccc1Br</smiles>

$(R)-\mathbf{h}$
6<smiles>OC(c1ccccc1)(c1ccccc1)c1ccccc1-c1ccccc1[C@@](O)(c1ccccc1)C(F)(F)F</smiles>

(66\%)

Scheme 4: Synthesis of 6.

(a)

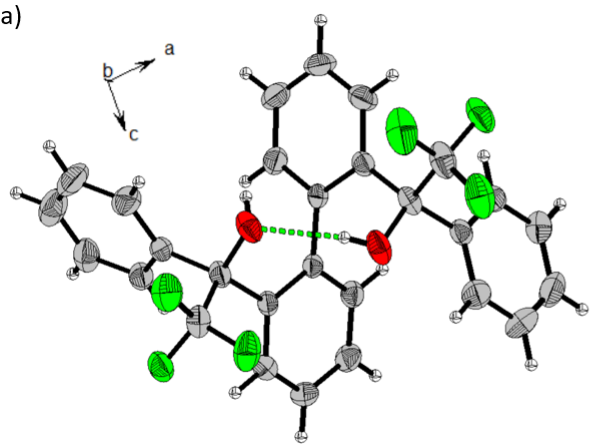

(b)

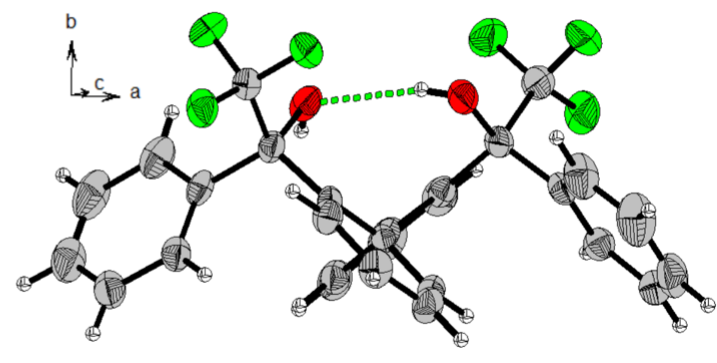

Figure 2: $\mathrm{X}$-ray crystal structure of $(P)-(S, S)-6$ at two different orientations to show (a) $P$ atropselectivities; (b) different relative spatial arrangement of the $\mathrm{CF}_{3}$ - and phenyl-substituents. Torsional angle of biphenyl rings is $104.55(22)$.

phenyl-4H-pyran-4-one). Unfortunately, benzaldehyde was found to be a challenging substrate and low enantioselectivities ( $2-8 \%$ ee) (Table 1 , entries $1-4)$ were obtained. The enantioselectivities can be improved slightly ( $32 \%$ ee and $11 \%$ ee) when $(P)-(R, R)-5$ and $(M)-(R, R)-5$ were employed as catalysts, although the yields decreased sharply (Table 1, entries 5 and 6). It should be noted that the absolution configuration of the catalytic product seems to be determined by the axial chirality $(P$ or $M$ ) of $\mathbf{5}$ rather than its point chirality at the side arms (both have the same $R$-chirality) [40]. The axial chirality of other catalysts have been reported previously to have a significant effect on controlling catalytic enantioselectivites $[41,42]$. For organocatalyst 6, it gave the highest enantioselectivity $(59 \%$ ee) but a low chemical yield.

When the bulkier trimethylacetaldehyde was used as substrate, the enantioselectivities were improved when 1-3 were used as catalysts (Table 1, entries 8-11). With 1 , the yield and enantioselectivity of the catalytic product (2,3-dihydro-2-tert-butyl-4Hpyran-4-one) were $50 \%$ and $12 \%$ ee (Table 1 , entry 8 ). The re- 
Table 1: Catalytic asymmetric oxo-DA reactions with stereolabile chiral biphenyl diols 1-6. ${ }^{\text {a }}$

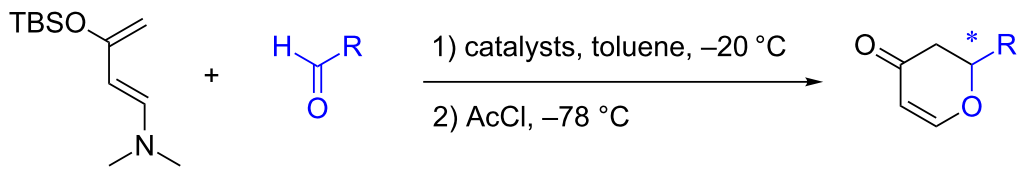

\begin{tabular}{|c|c|c|c|c|}
\hline Entry & Catalyst & Aldehyde & Yield $(\%)^{\mathrm{b}}$ & ee $(\%)$ (configuration) \\
\hline 1 & 1 & & 46 & $7(S)$ \\
\hline 2 & 2 & & 41 & $2(S)$ \\
\hline 3 & 3 & & 52 & $3(S)$ \\
\hline 4 & 4 & & 64 & $8(R)$ \\
\hline 5 & $(P)-(R, R)-5$ & & 15 & $32(S)$ \\
\hline 6 & $(M)-(R, R)-5$ & & 16 & $11(R)$ \\
\hline 7 & 6 & & 15 & $59(R)$ \\
\hline 8 & 1 & & 50 & $12^{\mathrm{e}}$ \\
\hline 9 & 2 & & 66 & $72^{\mathrm{e}}$ \\
\hline $10^{d}$ & 2 & & 26 & $74^{\mathrm{e}}$ \\
\hline 11 & 3 & & 28 & $16^{e}$ \\
\hline 12 & 4 & & 16 & $6^{e}$ \\
\hline 13 & $(P)-(R, R)-5$ & & 14 & $30^{e}$ \\
\hline 14 & $(M)-(R, R)-5$ & & 15 & $10^{e}$ \\
\hline 15 & 6 & & 16 & $10^{e}$ \\
\hline 16 & 2 & & 42 & $56(R)$ \\
\hline 17 & 2 & & 32 & $52^{f}$ \\
\hline 18 & 2 & & 33 & $43(R)$ \\
\hline 19 & 2 & & 30 & $36^{f}$ \\
\hline 20 & 2 & & 25 & $2^{f}$ \\
\hline
\end{tabular}

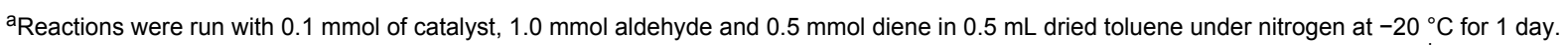
Then the reactions were worked up with $1 \mathrm{mmol}$ of $\mathrm{AcCl}$ at $-78{ }^{\circ} \mathrm{C}$. Products were isolated by column chromatography with silica gel. ${ }^{\mathrm{b}} \mathrm{lsolated}$ yields. 'Determined with HPLC with chiral columns, and the absolute configuration assigned by comparison with the order of elution of known compounds $[28,29,43]$. ${ }^{d}$ Reaction was performed at $-40{ }^{\circ} \mathrm{C}$ for 3 days. ${ }^{e}$ Absolute configuration undetermined. OD-H column, Hex:IPA $=98: 2,1 \mathrm{~mL} / \mathrm{min},(10.7 \mathrm{~min}$ and $11.6 \mathrm{~min}$ ) latter peak is a major peak for entries $8-12,14$ and 15 . Previous peak is a major peak for entry $13 .{ }^{\mathrm{f}} \mathrm{Absolute}$ configuration undetermined.

activity and enantioselectivity were significantly increased to $66 \%$ yield and $72 \%$ ee when 2 was employed as the catalyst (Table 1, entry 9). The enantioselectivity can be improved slightly to $74 \%$ when the temperature was decreased to $-40{ }^{\circ} \mathrm{C}$ (Table 1, entry 10). For 3 and $\mathbf{4}$, with aromatic substituents, the yields and enantioselectivities of the catalytic product decreased dramatically from 2 (Table 1, entries 11 and 12). For $\mathbf{5}$, similar to the case of using benzaldehyde as substrate, $(P)-(R, R)-5$ resulted in a higher enantioselectivity than $(M)-(R, R)-5$ and their products have opposite absolute configu- 
rations (Table 1, entries 13 and 14). For organocatalyst $\mathbf{6}$, the enantioselectivity was not as good as when using benzaldehyde as substrate (Table 1, entry 15).

In order to explore the scope of the present oxo-DA reaction, we next examined the reactions of other aldehydes with $\mathbf{2}$ as the catalyst. With less bulky aliphatic aldehydes, which only have hydrogens at the alpha positions such as isobutyraldehyde, 3,3dimethylbutyraldehyde, cyclohexylaldehyde and 2-phenylacetaldehyde, decrease in the yields and enantioselectivities were observed (Table 1, entries 16-19). With another aromatic aldehyde, 2-naphthaldehyde, a racemic product was obtained.

\section{Conclusion}

Three new chiral atropisomeric biphenyl diols 3, 4 and $\mathbf{6}$ with axial chiralities controlled by their corresponding additional asymmetric carbon centers were synthesized; despite having the same biphenyl scaffold, their highly enantioselective intermediates $\mathbf{b}, \mathbf{d}$ and $\mathbf{g}$ were obtained with different strategies: asymmetric reduction with oxazaborate catalyst for $\mathbf{3}$, chiral resolution with $(R)$-menthyl chloroformate for $\mathbf{4}$ and chiral resolution with (1S)-camphanic chloride for $\mathbf{6}$. Crystal structures revealed that the presence and absence of additional $\mathrm{CF}_{3}$ substituents in $\mathbf{3}$ and $\mathbf{6}$ led to very different structures, as $\mathbf{3}$ forms helical supramolecular structure with continuous and alternative inter- and intramolecular hydrogen bonds, whereas 6 forms a monomer without intermolecular hydrogen bonds for supramolecular formation. Together with compounds $\mathbf{1}, \mathbf{2}$ and $\mathbf{5}$, all were found to be active organocatalysts in oxo-DA reactions, with $\mathbf{2}$ resulting in the highest reactivity and enantioselectivity with trimethylacetaldehyde as a substrate. Opposite absolute configurations of the catalytic products of benzaldehyde from atropisomers of 5 showed that axial chirality contributes significantly to high enantioselectivities. Further works on organocatalyst optimization with different substituents are ongoing in our group and further experiments are underway to develop the use of these diols for other catalytic reactions.

\section{Supporting Information}

\author{
Supporting Information File 1 \\ Experimental data. \\ [https://www.beilstein-journals.org/bjoc/content/ \\ supplementary/1860-5397-15-92-S1.pdf]
}

\section{Acknowledgements}

The authors gratefully acknowledge the fundings from the Basic Research Program of Shenzhen (No. JCYJ20160531184120814), State Key Laboratory of Chemical Biology and Drug Discovery, and The Hong Kong Polytechnic
University [University Research Facility for Chemical and Environmental Analysis (UCEA)]. G.-L. Law gratefully acknowledges financial support from Natural Science Foundation of China (NSFC, 21875201)

\section{ORCID ${ }^{\circledR}$ iDs}

Wesley Ting Kwok Chan - https://orcid.org/0000-0002-5933-0181 Wai-Sum Lo - https://orcid.org/0000-0001-5329-4581

Ga-Lai Law - https://orcid.org/0000-0002-2192-6887

\section{References}

1. Jørgensen, K. A. Angew. Chem., Int. Ed. 2000, 39, 3558-3588. doi:10.1002/1521-3773(20001016)39:20<3558::aid-anie3558>3.0.co;2i

2. Corey, E. J. Angew. Chem., Int. Ed. 2002, 41, 1650-1667. doi:10.1002/1521-3773(20020517)41:10<1650::aid-anie1650>3.0.co;2b

3. Jørgensen, K. A. Eur. J. Org. Chem. 2004, 2093-2102. doi:10.1002/ejoc.200300766

4. Du, H.; Ding, K. Diels-Alder and Hetero-Diels-Alder Reactions. In Comprehensive Enantioselective Organocatalysis: Catalysts, Reactions, and Applications; Dalko, P. I., Ed.; Wiley-VCH: Weinheim, 2013; Vol. 3, pp 1131-1162. doi:10.1002/9783527658862.ch38

5. Ishihara, K.; Sakakura, A. Hetero-Diels-Alder Reactions. In Comprehensive Organic Synthesis, 2nd ed.; Knochel, P.; Molander, G. A., Eds.; Elsevier: Amsterdam, 2014; Vol. 5, pp 409-465. doi:10.1016/b978-0-08-097742-3.00510-3

6. Desimoni, G.; Faita, G.; Quadrelli, P. Chem. Rev. 2018, 118, 2080-2248. doi:10.1021/acs.chemrev.7b00322

7. Núñez, M. G.; García, P.; Moro, R. F.; Díez, D. Tetrahedron 2010, 66, 2089-2109. doi:10.1016/j.tet.2009.12.045

8. Taheri kal Koshvandi, A.; Heravi, M. M. Tetrahedron: Asymmetry 2017, 28, 1506-1556. doi:10.1016/j.tetasy.2017.10.030

9. Nicolaou, K. C.; Snyder, S. A.; Montagnon, T.; Vassilikogiannakis, G. Angew. Chem., Int. Ed. 2002, 41, 1668-1698. doi:10.1002/1521-3773(20020517)41:10<1668::aid-anie1668>3.0.co;2z

10. Eschenbrenner-Lux, V.; Kumar, K.; Waldmann, H. Angew. Chem., Int. Ed. 2014, 53, 11146-11157. doi:10.1002/anie.201404094

11. Chakraborty, T. K.; Tapadar, S. Tetrahedron Lett. 2003, 44 , 2541-2543. doi:10.1016/s0040-4039(03)00326-5

12. N'Zoutani, M.-A.; Pancrazi, A.; Ardisson, J. Synlett 2001, 769-772. doi:10.1055/s-2001-14601

13. Audrain, H.; Jørgensen, K. A. J. Am. Chem. Soc. 2000, 122, 11543-11544. doi:10.1021/ja003097y

14. Yasui, K.; Tamura, Y.; Nakatani, T.; Kawada, K.; Ohtani, M. J. Org. Chem. 1995, 60, 7567-7574. doi:10.1021/jo00128a032

15. Bednarski, M.; Danishefsky, S. J. Am. Chem. Soc. 1983, 105, 3716-3717. doi:10.1021/ja00349a064

16. Keck, G. E.; Li, X.-Y.; Krishnamurthy, D. J. Org. Chem. 1995, 60, 5998-5999. doi:10.1021/jo00124a001

17. Maruoka, K.; Itoh, T.; Shirasaka, T.; Yamamoto, H. J. Am. Chem. Soc. 1988, 110, 310-312. doi:10.1021/ja00209a061

18. Doyle, M. P.; Phillips, I. M.; Hu, W. J. Am. Chem. Soc. 2001, 123, 5366-5367. doi:10.1021/ja015692।

19. Togni, A. Organometallics 1990, 9, 3106-3113. doi:10.1021/om00162a023 
20. Gao, Q.; Maruyama, T.; Mouri, M.; Yamamoto, H. J. Org. Chem. 1992, 57, 1951-1952. doi:10.1021/jo00033a005

21. Ghosh, A. K.; Mathivanan, P.; Cappiello, J. Tetrahedron Lett. 1997, 38, 2427-2430. doi:10.1016/s0040-4039(97)00416-4

22. Yu, Z.; Liu, X.; Dong, Z.; Xie, M.; Feng, X. Angew. Chem., Int. Ed. 2008, 47, 1308-1311. doi:10.1002/anie.200704759

23. Kezuka, S.; Mita, T.; Ohtsuki, N.; Ikeno, T.; Yamada, T. Bull. Chem. Soc. Jpn. 2001, 74, 1333-1342. doi:10.1246/bcsj.74.1333

24. Lin, L.; Liu, X.; Feng, X. Synlett 2007, 2147-2157. doi:10.1055/s-2007-984917

25. Fan, Q.; Lin, L.; Liu, J.; Huang, Y.; Feng, X. Eur. J. Org. Chem. 2005, 3542-3552. doi:10.1002/ejoc.200500126

26. Du, H.; Zhao, D.; Ding, K. Chem. - Eur. J. 2004, 10, 5964-5970. doi:10.1002/chem.200400515

27. Huang, Y.; Unni, A. K.; Thadani, A. N.; Rawal, V. H. Nature 2003, 424, 146. doi:10.1038/424146a

28. Unni, A. K.; Takenaka, N.; Yamamoto, H.; Rawal, V. H. J. Am. Chem. Soc. 2005, 127, 1336-1337. doi:10.1021/ja044076x

29. Beemelmanns, C.; Husmann, R.; Whelligan, D. K.; Özçubukçu, S.; Bolm, C. Eur. J. Org. Chem. 2012, 3373-3376. doi:10.1002/ejoc.201200548

30. Friberg, A.; Olsson, C.; Ek, F.; Berg, U.; Frejd, T. Tetrahedron: Asymmetry 2007, 18, 885-891. doi:10.1016/j.tetasy.2007.03.018

31. Rajaram, S.; Sigman, M. S. Org. Lett. 2005, 7, 5473-5475. doi:10.1021/ol052300x

32. Jensen, K. H.; Sigman, M. S. Angew. Chem., Int. Ed. 2007, 46, 4748-4750. doi:10.1002/anie.200700298

33. Momiyama, N.; Tabuse, H.; Terada, M. J. Am. Chem. Soc. 2009, 131, 12882-12883. doi:10.1021/ja904749x

34. Villano, R.; Acocella, M. R.; Massa, A.; Palombi, L.; Scettri, A. Tetrahedron Lett. 2007, 48, 891-895. doi:10.1016/j.tetlet.2006.11.159

35. Zhuang, W.; Poulsen, T. B.; Jørgensen, K. A. Org. Biomol. Chem. 2005, 3, 3284-3289. doi:10.1039/b507778h

36. Goldfuss, B.; Rominger, F. Tetrahedron 2000, 56, 881-884. doi:10.1016/s0040-4020(99)01077-7

37. Yeung, C.-T.; Yeung, H.-L.; Chan, W. T. K.; Yan, S.-C.; Tam, E. C. Y.; Wong, K.-L.; Lee, C.-S.; Wong, W.-T. CrystEngComm 2013, 15 , 836-840. doi:10.1039/c2ce26438b

38. Yeung, C.-T.; Chan, W. T. K.; Lo, W.-S.; Law, G.-L.; Wong, W.-T. Molecules 2019, 24, No. 643. doi:10.3390/molecules24030643

39. Gliga, A.; Goldfuss, B.; Neudörfl, J. M. Beilstein J. Org. Chem. 2011, 7, 1189-1197. doi:10.3762/bjoc.7.138

40. For comparison, $(M)-(S, S)-5$ was observed to result in $(R)$ configuration and $(P)-(S, S)-5$ was observed to result in $(S)$ configuration of the catalytic products for this reaction, respectively.

41. Leven, M.; Müller, D.; Goldfuss, B. Synlett 2011, 2505-2508. doi:10.1055/s-0030-1260325

42. Leven, M.; Schlörer, N. E.; Neudörfl, J. M.; Goldfuss, B. Chem. - Eur. J. 2010, 16, 13443-13449. doi:10.1002/chem.201001106

43. Watanabe, Y.; Washio, T.; Shimada, N.; Anada, M.; Hashimoto, S. Chem. Commun. 2009, 7294-7296. doi:10.1039/b919535a

\section{License and Terms}

This is an Open Access article under the terms of the Creative Commons Attribution License

(http://creativecommons.org/licenses/by/4.0). Please note that the reuse, redistribution and reproduction in particular requires that the authors and source are credited.

The license is subject to the Beilstein Journal of Organic Chemistry terms and conditions:

(https://www.beilstein-journals.org/bjoc)

The definitive version of this article is the electronic one which can be found at:

doi:10.3762/bjoc. 15.92 